\title{
Consultants' experiences during their first year in post
}

\author{
Aisling Denihan
}

Obtaining one's first consultancy post in psychiatry, as in other specialties, marks the culmination of several years of study and training. It also heralds the transition from working as a supervised member of a team to functioning as an independent practitioner and team leader. This transition from senior registrar to consultant psychiatrist can prove difficult to negotiate and the stresses it provokes are commonly underestimated.

With some individuals eligible to apply for consultancy posts after only two years of higher training, it is clearly important to address the challenges facing them on taking up their appointments. Indeed psychiatrists may represent a particularly vulnerable group of consultants - research has shown that although psychiatrists report fewer clinical work demands than surgeons or physician colleagues, they are significantly more likely to report work-related emotional exhaustion and severe depression.'

The increasing shift towards a community-based model of psychiatric care is further exposing mental health care workers to higher levels of stress and exhaustion. ${ }^{2,3}$ Psychiatrists appear to be more susceptible to burn-out or low morale than psychiatric nurses, citing team conflicts and high workloads as the most difficult factors to contend with. ${ }^{4}$

There is a dearth of literature emanating from Ireland regarding how newly appointed consultant psychiatrists fare within the first year of taking up their posts. Indeed even in the British psychiatric literature this area has received scant attention. To bridge this gap in knowledge, the Irish Psychiatric Association conducted a survey assessing consultants' experiences during their first year in post.

Obtaining the list of consultant psychiatrists practising in the public system was the first step. The list was obtained by an application under the Freedom of Information Act to Comhairle na n-Ospideal. Between 1998 and 2004 there were 138 consultant psychiatry posts approved in Ireland. As of May 2004, 35 of these approved posts remained vacant.

This statistic is of interest in itself and begs an explanation - one wonders if it reflects a lack of planning at health board level. Individuals who had been in post for 12 months or more were targeted and a total of 89 survey questionnaires were posted with a brief covering letter explaining the purpose of the survey. The questionnaire was devised in such a way as to facilitate its completion in less than 10

Aisling Denihan, MB, BSc, MRCPI, MRCPsych, MD, Consultant Psychiatrist in Psychiatry of Older People, North Eastern Health Board. An Re Orga, Kennedy Road, Navan, Co Meath, Ireland. minutes. Information gathered included general details such as the speciality within psychiatry, the lead-in time from appointment to commencement, whether or not any induction was offered to individuals and the facilities and staffing levels made available to them.

The regularity with which consultants met with their consultant colleagues, clinical director and senior management personnel was recorded, as was the level of support they perceived as receiving from these sources. Their level of involvement and consultation in service planning was assessed and enquiries were made regarding their continuing professional development and pursuit of research interests. To the best of our knowledge this is the first attempt to gather such information on a national level.

The surveys were returned over an eight week period with a reminder posted to recipients at the four week stage. A response rate of $79 \%$ was obtained at eight weeks (three further surveys were subsequently returned but were excluded as the data were already analysed). This is an unusually high response rate for a postal survey where rates of $47 \%$ are the norm. ${ }^{5}$

The fact that such a large number of newly appointed consultant psychiatrists took the time to respond to the survey suggests that they regarded the topic as highly relevant and wished to share their experiences with others. The findings of the survey were presented in October 2004 at the annual general meeting of the Irish Psychiatric Association and are currently being written up for publication as a full article.

In general terms the survey findings make depressing reading, reflecting the low spend on mental health nationally and lack of organisation at local management level. Although in most instances health boards had adequate notice of consultants' starting dates, a lack of forward planning was common, resulting in inadequate (or no) facilities/staffing levels for the new consultant's team. The practice of appointing consultant psychiatrists in isolation is still common without allocating the additional resources required to ensure that he or she can provide even the most basic of clinical services.

A fairly typical experience of a new appointee was to meet an administrator on their first day who would then hunt around for office space for the new consultant. It was not unusual for a consultant to have to wait several months before they could start accepting referrals from general practitioners due to lack of facilities and support staff.

At 12 months, 40\% of respondents were still lacking either an NCHD, community mental health nurse, clerical worker or office. Lacking even these basic requirements, it is hardly surprising that many newly appointed consultants 
experience a strong sense of frustration and disillusionment early in their career. Consultants are also expensive personnel and it is wasteful of public money to employ them without providing the necessary infrastructure required by them to complete their duties.

Multidisciplinary teams are increasingly advocated as the preferred means of delivering mental health care to individuals. The term is often bandied about with little thought as to what exactly constitutes a true MDT.

The reality on the ground is that just $18 \%$ of consultant psychiatrists were able to access a social worker, a psychologist or an occupational therapist one year after they had set-up their service. Such professionals are considered essential for the provision of multidisciplinary care to people with psychiatric illness. Such are the barriers that newly appointed psychiatrists encounter in trying to provide a quality service to patients.

Of respondents, $62 \%$ perceived that they were not being adequately supported by hospital/health board management in their endeavours in setting-up and running their service. While lack of resources is certainly a factor, this highlights the gap between consultants and management and the need for better lines of communication between the two.

The wish lists of newly appointed consultants were broadly similar, indicating that the problems are not unique to any one specialty within psychiatry or any one health board. Aspirations included more responsive, engaged administrators, adequately resourced mental heath services, proper facilities, supportive colleagues and clinical directors and the provision of true multidisciplinary teams.

Mentoring for newly appointed consultants was also called for, as was the provision of protected time for the pursuit of research and teaching interests.

New appointees are full of enthusiasm, keen to implement change and provide the best service possible for their patients. It must be recognised that they need support to do this, both by the tangible provision of resources and facilities, and the less tangible (but not to be under-estimated) emotional support of colleagues and mentors.

\section{References}

1. Deary I, Agius R, Sadler A. Personality and stress in consultant psychiatrists. Int J Soc Psychiatry 1996; 42: 112-3.

2. Prosser D, Johnson S, Kuipers $E$ et al. Mental health, 'burnout' and job satisfaction among hospital and community-based mental health staff. Br J Psychiat 1996: 169: 334-7.

3. Prosser D, Johnson S, Kuipers E et al. Mental health, 'burnout' and job satisfaction in a longitudinal study of mental health staff. Soc Psychiatry Psychiatr Epidemiol 1999; 34: 295-300.

4. Galeazzi G, Delmonte S, Fakhoury W et al. Morale of mental health professionals in community mental health services of a northern Italian province. Epidemiol Psychiatr Soc 2004; 13: 191-7.

5. Yu J, Cooper $\mathrm{H}$. A quantitative review of research design effects on response rates to questionnaires. J Marketing Res 1983; 20: 36-44.

\section{Cover image: 'The Kiss'}

The Irish Museum of Modern Art's (IMMA) aim is the collection and presentation of modern and contemporary art. The Museum's mission is to foster within society, an awareness, understanding and involvement in the visual arts. The mental health service users of St Martha's Project, at St James's Hospital, took part in iMMA's Focus on... programme. The participants focused on their own response to an exhibition of work by the artist Vik Muniz. The artist's reproduction of famous 'old masters' using different kinds of foodstuffs, facilitated the introduction of materials, techniques and concepts not usually associated with art. This resulted in a collaboration of clever, innovative images, including 'The Kiss', that were as much fun to view, as they were to create. The work was exhibited at IMMA and St James's Hospital. 